\title{
DO NOT TRUST ME: HOW NEWS READERS PERCEIVE AND RECOGNIZE NATIVE ADVERTISING
}

\author{
Valerio Stallone \\ Zurich University of Applied Sciences, Center for Digital Marketing. Theaterstrasse 17, CH-840I \\ Winterthur, Switzerland \\ Maastricht University. 6200 Maastrich, MD, The Netherlands
}

\begin{abstract}
Native advertising has developed into a popular marketing tool for publishers and advertisers. However, its success is also criticized, because it is assumed that readers are not able to identify these contributions as advertising. The purpose of this study is to outline whether readers recognize native ads and how it affects the trust in the content of the articles. It is also intended to help advertisers and publishers better understand the impact of native advertising and its disclosure on readers. The method of this research is based on a theoretical and empirical approach. For the theoretical aspects of this study, a literature analysis was applied, whereas a quantitative analysis in the form of an experiment was conducted for the empirical part. The study shows that a majority of the sample did not recognize the article as native ad. After the disclosure of native advertising a decrease in trust could be determined. However, this is not significant, which means that the majority of readers still trust the content of the article. It is also found that respondents for whom the content of the article is relevant are less concerned about the article being paid for. Thus, it can be said that the success of native advertising may in fact be related to the inability of readers to recognize this type of advertising. The increased recognition of such contributions, however, does not necessarily lead to a reduced success of native advertising, because the majority of contributions are trusted even after disclosure.
\end{abstract}

\section{KEYWORDS}

Online Marketing, Native Advertising, Ad Recognition, Trust

\section{INTRODUCTION}

Internet users increasingly find themselves in digital communication spaces such as social networks, forums and editorial online media (Tuna \& Ejder, 2019). Especially the internet access through various devices, such as smartphones and tablets, leads to more users being 
IADIS International Journal on WWW/Internet

online (Keuper, Hamidian, Verwaayen, Kalinowski, Kraijo, 2013; Tuna \& Ejder, 2019). Based on this insight, companies are increasingly turning to digital advertising to reach potential customers (Tuna \& Ejder, 2019). As a result, users are exposed to an increasing number of advertisements in the form of adverts and banner ads, which are often perceived as intrusive and annoying (Sandvig, Bajwa \& Ross, 2011). Therefore, users are increasingly installing ad blockers to bypass banner ads or they no longer perceive them (so-called "banner blindness") (Sandvig et al., 2011; Tuna \& Ejder, 2019). This behavior endangers the revenue models of publishers who sell advertising space to advertisers on online media platforms. These are offset by the number of hits or clicks and lose attractiveness due to this banner blindness (Sandvig et al., 2011; Tuna \& Ejder, 2019). In addition, advertisers no longer reach their target groups, which reduces revenues (Sandvig et al., 2011; Tuna \& Ejder, 2019). As a result, the importance of native advertising among advertisers and publishers is increasing (Wojdynski \& Evans, 2016). This opinion is also held by the research companies Enders Analysis and eMarketer (Statista, 2018), which forecast an increase in advertising expenditure for native advertising in Europe to over 13 billion euros in 2020. For example, a paid contribution is posted in the form of an article on an online media platform. The aim is to address readers in their familiar editorial environment and offer them added value (Interactive Advertising Bureau Switzerland [IAB Switzerland], 2017). In contrast to conventional online advertising, the focus is not on the company, the brand or the product, but on topics that are relevant to the user (Tuna \& Ejder, 2019). The key purpose of the presented study is to outline whether readers recognize native ads and how this type of advertising can affect the trust in the content of the contribution. The question arises as to whether the content continues to appear trustworthy or whether it is being questioned in a particularly critical manner. Furthermore, the study offers practical insights to publishers and advertisers by helping them understand the impact of native advertising and their disclosure to readers.

This paper is located in the field of digital marketing, in the category of Native Advertising. Various forms of native advertising can be found here. In this paper only the format Native Advertorial will be discussed, which will be explained further. The reason for this limitation is that this format is used in empirical studies or experiments. Further Native Advertising formats and alternatives to Native Advertising are not the subject of this paper. Furthermore, this paper focuses on the Swiss market.

\section{LITERATURE REVIEW}

Different articles in literature point out, that the success of native advertising could be linked to the fact that readers do not recognize such contributions as advertising (Carlson, 2015; Wojdynski \& Evans). Furthermore, Wojdynski and Evans (2016) concluded that readers who could identify native advertising questioned the credibility of the contribution.

Literature discusses whether the effectiveness of native advertising is related to readers not recognizing native ads as advertising (Carlson, 2015; Wojdynski \& Evans, 2016). Although the guidelines and industry recommendations of advertising institutions (Interactive Advertising Bureau [IAB], 2013; IAB Switzerland, 2017) call for clear and conspicuous labelling of sponsored articles, little scientific research has been conducted into this so far. It must be clarified whether readers recognize such labels, how they are perceived and how they affect trust in the content of the articles. Thus, it is of particular interest to conduct further research in this area of marketing. The following chapters show the current state of research on the recognition of native ads by readers and the impact on trust. 


\subsection{Demarcation of the Definition}

Based on the definitions of Native Advertising in the previous subchapter, it is evident that the term "content marketing" is often used in the definitions. According to Tuna and Ejder (2019) and Ottersbach (2018), both terms are often used as synonyms, not least because of their unclear definitions.

In order to create a uniform understanding of Native Advertising, a clear differentiation to the term Content Marketing essential for this bachelor thesis. On the website of the Content Marketing Institute (n.y.) the term Content Marketing is described as follows: "Content marketing is a strategic marketing approach focused on creating and distributing valuable, relevant, and consistent content to attract and retain a clearly defined audience - and, ultimately, to drive profitable customer action". Accordingly, content marketing is a strategic decision that focuses on creating relevant content for a defined target audience (Content Marketing Institute, n.y.). The content should be informative, entertaining or advisory in order to leave a positive impression on the readers. The aim is to convince potential customers of the advertiser and to strengthen the loyalty of existing customers (Eugster, 2015).

The content is distributed via the distribution channels Owned Media and Paid Media. Owned media includes online activities that are implemented and managed by an advertiser himself, such as corporate websites, blogs, newsletters, apps and his own social media platforms (Kreutzer, 2018; Tuna \& Ejder, 2019). Paid media are channels of publishers that are characterized by their own editorial offers. Advertisers' content can be embedded as advertising on such channels (Tuna \& Ejder, 2019). This is where the distinction between content marketing and native advertising is made. Consequently, content marketing uses the vehicle of native advertising for the distribution of content via paid media (Tuna \& Ejder, 2019).

\subsection{Forms of Native Advertising}

The merging of paid and editorial content was already used before the World Wide Web era. One example is the use of advertorials in print media in 1960 (Wojdynski, 2016a). The term "advertorial" is derived from the combination of the two words advertising and editorial and, according to Wojdynski (2016a), refers to advertisements in the form of articles published in magazines and newspapers. The transfer of this business model to online publications was realized with the current Native Advertising (Tuna \& Ejder, 2019). Thus, the advertorial can be counted among a possible original format of Native Advertising (Matteo \& Dal Zotto, 2015, Tuna \& Ejder, 2019, Wojdynski, 2016a).

In the literature of Ming and Yazdanifard (2014) and of Tuna and Ejder (2019), the digitally extended form of advertorial, is referred to as "Native Advertorial". The authors Tuna and Ejder (2019) provide the following description of Native Advertorial:

"A Native Advertorial refers to a paid article that is visually and contentwise aligned with the medium in which it appears. It is created by the publisher's editorial staff, is marked as an advertisement and is usually published on a publisher's website for a fixed period of time".

In connection with the above description, it should also be mentioned that the article was published in cooperation between the publisher's editorial staff and the advertiser is being created (Tuna \& Ejder, 2019). 
IADIS International Journal on WWW/Internet

Furthermore, the literature of Tuna and Ejder (2019) mentions that, ideally, Native advertorials are not advertised with pure advertising messages and "buy-me" attributes, but with content that might interest the reader. The advertising content can be published in the form of an article, a column, a story or any other attribute (Wojdynski, 2016a). In addition to texts, this content can also consist of images, audio and video material (Tuna \& Ejder, 2019). Native advertorials are usually not prevented by advertising blockers (Ming \& Yazdanifard, 2014; Tuna \& Ejder, 2019). There is no generally applicable definition of the forms of Native Advertising. Consequently, the same elements of the above-mentioned definition of native advertorial can be found in other definitions, such as sponsored content (Wojdynski, 2016a).

\subsection{Legal Framework}

In the case of native advertising, advertising should be closely related to the content that appeals to the reader (IAB Switzerland, 2017; Eugster, 2015; Marti, 2017). What is controversial here is that this mixture is not entirely consistent with existing and ethical principles, such as the principle of separation (Marti, 2017). The separation rule refers to the fact that editorial content should be clearly separated from advertising content. In doing so, the reader must not be in any doubt as to whether a content originates from the website operator or whether third parties have paid for it (Schirmbacher, 2017). Advertising content must be made recognizable as such in this respect unless this is clearly evident from the content (e.g. banner advertising). A violation of the bid corresponds to a breach of the Unfair Competition Act (Schirmbacher, 2017). The aim of the separation rule is thus that readers can easily recognize the advertising as such and that deception is prevented. On the other hand, the specialist literature on native advertising doubts that readers will recognize native advertising as such (Wojdynski \& Evans, 2016; Wojdynski 2016b), which means that there is a risk that the advertising will be deceptive for the reader. This means that Native Advertising is in a legal limbo between legality and illegality. Due to the lack of judicial decisions to date, it is unclear to what extent the separation rule applies to the various types of native advertising (Marti, 2017).

For the reasons mentioned above, affected industry associations and organizations are relying on self-regulation. In addition to the already existing laws of the UCA, they develop non-statutory guidelines and recommendations, so-called soft laws (Marti, 2017). By means of these guidelines and recommendations, a clear boundary should be created with regard to native advertising and the separation requirement (e.g. IAB Switzerland, 2017). Sufficient disclosure is essential, so that readers can recognize the advertising content. However, a violation of the soft law guidelines cannot be asserted in court (Marti, 2017). Nevertheless, it is possible for state courts to orient themselves to the provisions of soft law customary in the industry and to call upon these for their jurisdiction (Marti, 2017).

The associations operating in Switzerland, with regard to the establishment of guidelines and recommendations include the Swiss Commission on Fair Trading and the IAB Switzerland. At this point, it is important to mention that there are no universal standards for the type of disclosure. This can be illustrated using the example of IAB Switzerland (2017). Although this association requires the media to label the Native Ads, the choice of words and the presentation is up to the publisher himself. 


\subsection{Recognition of Native Ads by Readers}

The article "Native Advertising: Engagement, Deception, and Implications for Theory", written by Wojdynski (2016a), analyses the effect of native advertising's disclosure in greater depth. Wojdynski (2016a) is of the opinion that the use of labels for the disclosure of advertising is the only feature that consistently distinguishes paid content from editorial content; this is the case in many native advertising examples. Consequently, the way in which disclosure is presented should be the decisive determinant for the probability that readers confuse advertising with ordinary editorial content (Wojdynski, 2016a). Wojdynski (2016a) describes two successive processes that must be carried out in order for disclosure to be effectively processed by the reader. The first process is about the attention that disclosure should bring about, and the second process is about understanding. The disclosure language should therefore convey the information that an advertiser paid for the content presented and may have been involved in determining the content. According to Wojdynski (2016a), it is complex to identify unique design features that increase readers' understanding and attention. Nevertheless, empirical studies show that certain disclosure characteristics can increase the likelihood that readers will pay more attention to them or identify them as advertising (Wojdynski \& Evans, 2016). A study by Wojdynski and Evans (2016.) provides a detailed overview of the current practices of native advertising disclosure. The results show that approximately $79 \%$ of readers overlooked the disclosure label. This was particularly the case when the characteristics were above the article (Wojdynski \& Evans, 2016). Of all the participants, only a few (7\% in the first experiment and $18.3 \%$ in the second experiment) could recognize that the article was paid advertising (Wojdynski \& Evans, 2016). Furthermore, the labels "sponsored content" or "advertising" led to a higher recognition of advertising than an unclear disclosure language, such as "presented by" and "brand voice" (Wojdynski \& Evans, 2016). The same study also showed that the positioning of disclosure can also be a significant feature for recognition. For example, a mid-positioned disclosure could lead to an increased recognition of the advertisement as a positioning above or below the text (Wojdynski \& Evans, 2016). It should be noted at this point that the disclosure practices mentioned are not the only features that influence the recognition of native ads. For example, direct mention of the sponsor, inclusion of certain product or purchase information, and visible logos and links to sponsors' websites may also lead to increased recognition of native advertising (Wojdynski, 2016a). The study "The Deceptiveness of Sponsored News Articles: How Readers Recognize and Perceive Native Advertising" by Wojdynski (2016b) showed that the presence of a logo increases the chances of recognition. However, the presence of the logo also led to misconceptions on the part of the participants that this was an independent display advertising. Wojdynski and Evans (2016) state that further research is necessary. Considering these findings and in alignment with the purposes of this study, the first hypothesis could be derived.

Question 1: Do readers recognize native ads as advertising?

Hypothesis 1: In the experimental group, in contrast to the control group, the respondents will increasingly recognize the native ad as an advertising medium.

The first hypothesis aims to measure the recognition of native ads between the experimental and control groups. It is assumed that the respondents of the experimental group increasingly recognize the native advertisement due to the differentiated disclosure representation. This assumption is based on the disclosure practices mentioned by Wojdynski (2016a), which may lead to an increased recognition of native advertising. To test the first hypothesis, an expected 
value of $51 \%$ is defined for the term "increasingly". Therefore, respondents from both groups who recognized the native ad are compared. To a detailed explanation of the disclosure presentation, the groups and their classifications will be dealt with further in chapter 3 .

\subsection{Trust in the Content of the Contribution}

An experiment by Cole and Greer (2013) shows that readers trust content in a journalistic format more than advertising. Even if an article is labeled as advertorial, the reader's perception does not change much (Cole \& Greer, 2013). It can therefore be concluded that readers trust an advertorial almost as much as they trust a journalistic text. The identification of the advertising content as such does not seem to have any negative impact on reader trust.

Wojdynski (2016b) believes that the ability to recognize a particular message as advertising is an important determinant of the way the message affects readers' attitudes. He also mentions that participants who receive a hint about an attempt to persuade are less likely to receive the content than participants who do not receive such information. This statement can be supported by the experiment of Wojdynski and Evans (2016). The research found that readers who recognized the advertising had a more negative perception of the credibility of news. Wojdynski (2016b) recommends that future research should show in greater depth how consumers perceive the information in native advertising and how various disclosure designs can be used to attract more attention and understanding. According to the above findings, the second hypothesis could be derived.

Question 2: How does native advertising affect the trust in the content of the article?

Hypothesis 2: A large proportion (60\%) of the respondents are likely to lose their trust in the content of the article.

The second hypothesis examines the number of respondents who are likely to lose trust in the content of the article after it has been revealed that it is native advertising. The change in attitude is measured using the "trust" factor. The assumption that the respondents will lose trust in the content of the article after disclosure comes from a study by Wojdynski and Evans (2016). The results show that the respondents who recognized the advertisement had a more negative perception of the credibility of the message. Therefore, it is assumed that more than half of the respondents (expected value 60\%) lose trust in the content of the article.

\section{METHODOLOGIES}

The current state of research shows that further investigations are necessary in the areas of recognition and the resulting These issues will be investigated by means of an experiment. The following chapters describe the methodological procedure for collecting the necessary data for this research. At the beginning the method of investigation is explained, which serves to answer the research question of this thesis. Afterwards, the collected data are analyzed and presented. 


\subsection{Experimental Design}

The research design used for the empirical analysis of this study corresponds to a quantitative research in the form of an experiment. The comparison group design according to Kuper (2011) was used. The participants are divided into two groups and are each exposed to a stimulus (Kuper, 2011; Scholl, 2009). For the experiment to be carried out, the experimental group receives an article with the additional disclosure characteristics: the label "Sponsored", a disclosure text and the advertiser's logo on the right side (Stimulus A). The control group is assigned the same article without the mentioned additional disclosure features on the right side (stimulus B). This creates two experimental conditions. For this experiment, the presence or absence of the additional disclosure characteristics are defined as independent variables.

\subsection{Sampling Procedure}

The respondents are selected according to the arbitrary method of the snowball principle (Leila, 2014; Brosius, Haas and Koschel, 2012). For this purpose, an automatically generated link to the survey is sent to private and business contacts. The respondents are asked to participate in the survey and to forward the link. The aim of this request is to obtain a larger and more diversified sample. In addition to active recruitment according to Brosius et al. (2012), passive recruitment is also included. The aim is to establish contact with potential respondents by making references in forums or on websites (Brosius et al., 2012). In this study, the corresponding link is shared on social media (Facebook and Instagram). The potential sample members are asked to participate in the survey and to forward the link or share it on their own social channels. According to Brosius et al (2012), this method also corresponds to an arbitrary selection.

\subsection{Selection and Manipulation of the Article}

An article was taken from the online news platform " $20 \mathrm{~min} . \mathrm{ch}$ " as an image file. The image file was used to provide two versions of the article for the survey. The versions differ in the presence and absence of the label "Sponsored", the disclosure text "This article was produced by Commercial Publishing Tamedia in collaboration with Gesundheitsförderung Schweiz" and the logo "Friendly Work Space" in the right column. The manipulations carried out on the article or the image file are explained in as follows. 
IADIS International Journal on WWW/Internet

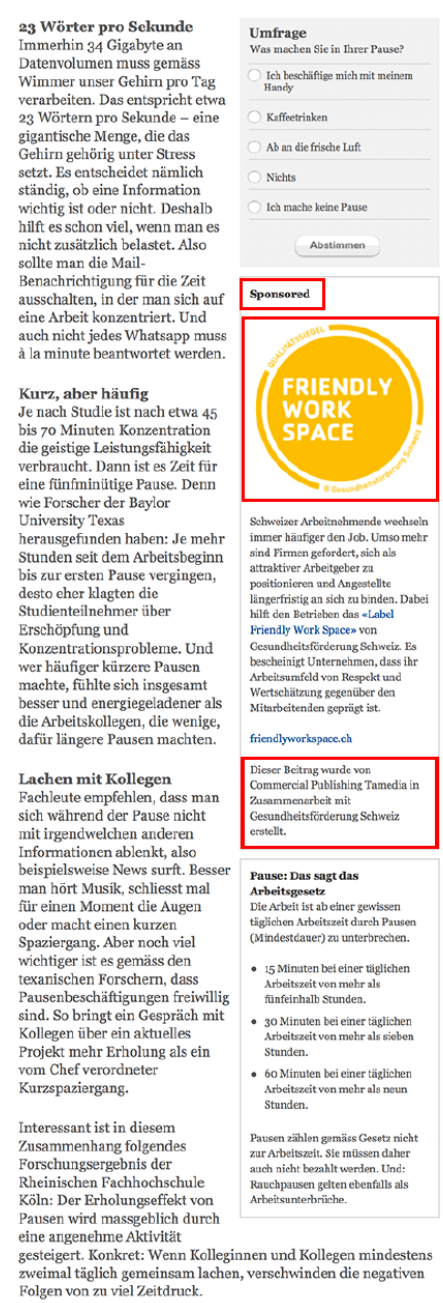

Figure 1. Screenshot of Stimulus A

In the first article (Stimulus A, see Figure 1), a change was made to the original version on the online news platform. For example, a video below the article was removed because the article is implemented in the survey as an image file. Therefore, the video is not part of the survey. No other changes were made in the article to generate a scenario that was as realistic as possible. 


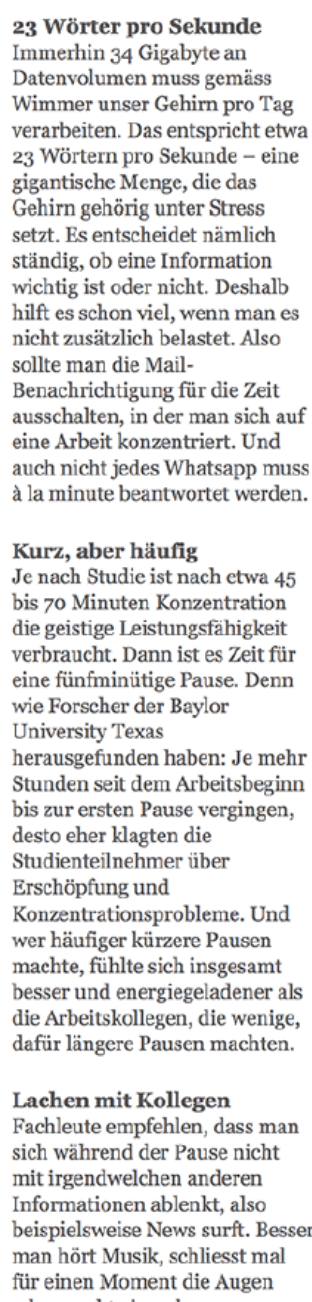

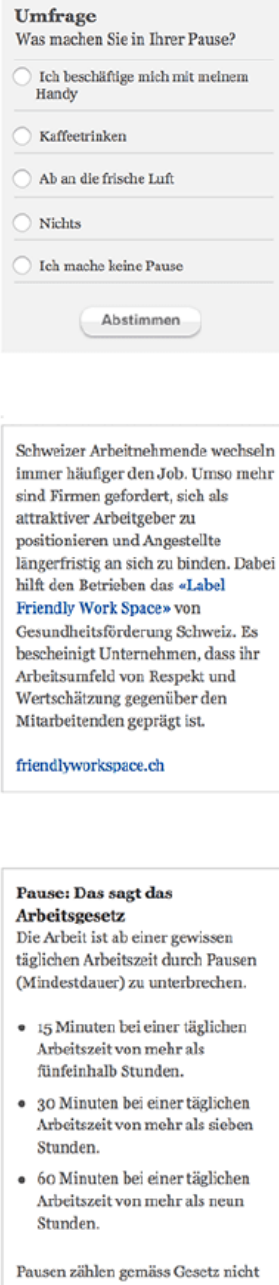

- 60 Minuten bej einer tägliche Arbeitszeit von mehr als neun Stunden.

Pausen zählen gemäss Gesetz nicht

Figure 2. Screenshot of Stimulus B

The second version of the article (Stimulus B, see Figure 2) corresponds to the first version without the label "Sponsored", the disclosure text and the logo "Friendly Work Space" in the right column. The differences in the articles are also intended to show whether a certain change in the presentation of the disclosure characteristics affects recognition.

\subsection{Survey}

The online survey mainly contains closed questions with predefined answer categories. These make it easier to answer the questions, lead to higher response rates and minimise difficulties in processing the data (Kuss et al., 2014). In addition, efforts are made to ensure that the responses are balanced. For example, one response category used for the survey is as follows: 
IADIS International Journal on WWW/Internet

"I completely agree", "rather agree", "neither", "rather disagree" and "not agree at all". Aside from the closed questions, two open questions are also formulated. These questions are used to check whether the respondents determine the correct positions of the advertising and correctly perceive the form of advertising. In addition, a half-open question is asked, which is supplemented by an optional text field called "Other" in addition to the answers listed. This option represents a text field to be filled in which other answer options are considered by the respondents. According to Kuss et al. (2014), the completeness of the categories should be guaranteed. A 5-point Likert scale is used for the evaluation of the questions. For this purpose, a positive and a negative range are defined. The positive range is an average above 3.00 , while the negative range is an average below 3.00 .

\subsection{Data Collection}

The data collection took place between 01 April 2019 and 19 April 2019. The link to the survey was shared on the social media and sent directly to individual respondents. By clicking on the corresponding link, the respondents reached the survey, which had to be completed online. All questions were marked as mandatory so that the respondents were forced to give complete answers before moving on to the next block of questions. A "back button" was deliberately omitted in order not to change the answers to the questions of the experiment afterwards.

\section{FINDINGS}

In the following subchapter the analysis of the collected data takes place. In a first step, the data is cleaned up to ensure a clean analysis. Subsequently, the sample, including the size and composition of the present study, is presented. Furthermore, the results are evaluated descriptively before the hypotheses set out before are finally checked and evaluated.

\subsection{Data Cleansing}

After the experiment was completed, the collected data was exported from the survey tool "Umfragen Online" and transferred to the IBM statistics program SPSS 25. The data set was first checked for missing values and a too short implementation time of the survey (under 4 minutes).

Missing values are due to unanswered questions, which means that the respondents have not completed the survey. Consequently, the answers of these 90 respondents were not taken into account for the survey, which reduced the number of respondents to 255 . In a further step, the respondents' answers to the two test questions in the survey were checked. The test questions being related to the content of the contribution itself. The evaluation of the test questions was based on single choice. Accordingly, the respondents' answers were evaluated as correct or incorrect. The results show that a total of four of the 255 test persons answered one or both questions incorrectly. Consequently, the answers of these test persons were also excluded for further analysis, as they did not read the text, or did not read it accurately, and could therefore distort the results. 


\subsection{Sample Size and Composition}

The study consisted of a sample of 251 respondents. The sample composition was analysed according to the sociodemographic characteristics of the respondents. Due to the experimental conditions of this study, an in-depth analysis of the collected data was performed. The 251 respondents were assigned to the following two groups: Experimental group and control group. A random allocation was not possible in the survey tool used. Due to this an unconscious distribution was made by the respondents themselves by asking them to select a number from one to ten. The results show that $118(47 \%)$ respondents were assigned to the experimental group and 133 (53\%) to the control group. Furthermore, the sociodemographic characteristics "age" and "gender" per group were analysed. The experimental group has more male than female respondents. On the other hand, more female respondents are represented in the control group. A comparison of the age distribution within the groups showed that the majority $(55.8 \%$ in total) of the respondents belong to the age group 18-29. The lowest numbers of respondents in both groups were under 18 and over 60 . Based on the results of this study, it can be concluded that an even distribution of the age groups is not given. This finding also applies to the results within the experimental and control group. The analysis of the sociodemographic characteristic "highest educational attainment" revealed that the vocational apprenticeship had the highest value in both groups (34.6\% in total). This is followed by the Bachelor's degree (26.7\% in total).

\subsection{Descriptive Results}

In this subchapter the results of the empirical investigation are presented. To provide a better overview, they are divided into the following three sections: Recognition of the Native Ads, confidence in the content of the article and the respondents' attitude towards the article.

\subsubsection{Native ad Recognition}

The first part of the research question "do readers recognize native ads as advertising?" examines the influence of disclosure characteristics (label "Sponsored", logo "Friendly Work Space", disclosure text) the reader's ability to correctly identify the article as a native ad. The respondents were asked three questions which will be analysed with regard to the results in the following. According to Table 1, in total, $83(33.1 \%)$ respondents answered the question "did you notice any advertising content while reading the article?" with "yes". Almost twice as many respondents from the experimental group recognized advertising content. When answering question above with 'yes', two open questions ("Please indicate where" and "Describe this advertisement in your own words") on the recognition of advertising followed. These filter questions were used to check whether the respondents were able to recognize the native ad based on the right criteria. The answers were calculated as follows: 1. respondents, who have identified the article as advertising (native ad), 2. respondents who have recognized the disclosure characteristics 3. respondents who have perceived other advertising content and 4. respondents, whose answers cannot be classified (similar to the evaluation method from Wojdynski, 2016b, p. 9). The results show that five $(6 \%)$ of the 83 respondents perceived the article as advertising and thus as native ad (category 1 ). 
IADIS International Journal on WWW/Internet

Table 1. Recognition of native advertising by the experimental and control group

\begin{tabular}{llrrr}
\hline Group & Details & \multicolumn{3}{c}{ Native ad recognized } \\
\cline { 2 - 5 } & & Yes & No & \multicolumn{1}{c}{ Total } \\
\hline Experimental group & Amount & 54 & 64 & 118 \\
& \% in this group & $45.8 \%$ & $54.2 \%$ & $100 \%$ \\
\multirow{3}{*}{ Control group } & \% in native ad recognized & $65.1 \%$ & $38.1 \%$ & $47 \%$ \\
& Amount & 29 & 104 & 133 \\
& \% in this group & $21.8 \%$ & $78.2 \%$ & $100 \%$ \\
Total & \% in native ad recognized & $34.9 \%$ & $61.9 \%$ & $53 \%$ \\
& Amount & $\mathbf{8 3}$ & $\mathbf{1 6 8}$ & $\mathbf{2 5 1}$ \\
& \% in this group & $\mathbf{3 3 . 1 \%}$ & $\mathbf{6 6 . 9 \%}$ & $\mathbf{1 0 0 \%}$ \\
& \% in native ad recognized & $\mathbf{1 0 0 \%}$ & $\mathbf{1 0 0 \%}$ & $\mathbf{1 0 0 \%}$ \\
\hline
\end{tabular}

Despite the conditions of "non-existence of disclosure characteristics", three $(60 \%)$ respondents in the control group identified the article as advertising. The remaining two (40\%) belonged to the experimental group. In order to determine the reason for the recognition of native ad, the answers of these respondents are analysed more thoroughly. The answers show that two respondents of the control group perceived the label "Sponsored" and were able to interpret it. Another respondent in this group explicitly described the article as a "native product". In the experimental group, the responses of the two respondents were "sponsored article" and the position was given on the right. As a result, the two respondents were able to identify the article as advertising due to the disclosure features on the right side. In addition, the age group and gender were examined to determine possible patterns. The three respondents from the control group could be assigned to the age group 18-29 while the two respondents from the experimental group corresponded to the age between 30 and 39. In addition, all five respondents were male. Due to the small sample, no statements were made about the population. The second category has the highest number of respondents. Due to the condition "presence of disclosure characteristics", only respondents of the experimental group are found in this category. The results show that $59.3 \%$ of the respondents in the experimental group recognized the disclosure characteristics but could not conclude that they were native ad. In the fourth category, more than half $(55.2 \%)$ of the answers from the control group could not be classified. Similar results were also achieved in the experimental group, with the fourth category having the second highest number of answers $(25.9 \%)$.

\subsubsection{Trust in the Content of the Contribution}

The second part of the research question "How does this form of advertising affect the trust in the content of the contributions" examines the "trust" factor of the respondents. The respondents were asked two questions which explicitly measured their trust. One question was asked before and the other after the disclosure of native advertising. The results in table 2 show a decrease in trust after the advertising content has been disclosed.

Table 2. Trust of the surveyed users in the content

\begin{tabular}{lrr}
\hline Group & \multicolumn{2}{c}{ Disclosure } \\
\cline { 2 - 3 } & Before & \multicolumn{1}{c}{ After } \\
\hline Experimental group & 3.76 & 3.03 \\
Control group & 3.82 & 3.06 \\
Recognized & 3.71 & 3.01 \\
Not recognized & 3.2 & 3.2 \\
Total & $\mathbf{3 . 7 8}$ & $\mathbf{3 . 0 3}$
\end{tabular}


Nevertheless, the results of the mean $(\mathrm{MD}=3.033)$ were in the positive range and the respondents continued to trust the content. This indicates that the respondents still have a slightly positive attitude towards the article despite the loss of trust. If the results are additionally compared between the experimental and control groups, it can be stated that the presence or absence of the additional disclosure characteristics did not cause any significant difference in the results.

\subsubsection{Attitude towards the Article}

In this section, the attitude of the respondents towards the article or native ad is evaluated. In order to get a better overview, the results were divided into the following categories: (1) respondents' attitude to the article before disclosure (2) respondents' attitude to the article after disclosure and (3) respondents' intention to share information. It should be noted that the trust questions were also included in the respondents' attitudes towards the article and were therefore included in the evaluation. In the first category, "respondents' attitude to the pre-disclosure article", the results showed a positive attitude towards the article with a mean of $\mathrm{MD}=3,645$. In particular the question "The information in the article was helpful" has a high value. Consequently, in addition to trust, the relevant content for the respondents seems to be an important point for the positive attitude towards the article. In a further step, the second category "attitude of the respondents towards the article after disclosure" was analysed. The results show an average value of $\mathrm{MD}=3,186$. Although this value is lower than before the disclosure of native advertising, the respondents show still a positive attitude towards the article. Especially striking is the result of the question "How do you feel about the article since you know that it is a form of advertising?".

With an average value of $\mathrm{MD}=2.69$, the question shows a negative attitude towards native advertising. This result contradicts the results, which show the questions "I don't care if it is a paid article as long as the content is relevant for me" and "As long as the article is interesting, the advertising content doesn't bother me". The results of these two questions show a rather positive attitude towards native advertising. Consequently, the change in the attitude towards native advertising can be explained by the fact that as long as the content is interesting or relevant for the respondents, the native ads not further perceived as disturbing. Finally, the responses to the third category, "Intention of respondents to share information", were evaluated. The results show a mean value of $\mathrm{MD}=2,387$. Therefore, the results do not indicate any intention to share the information or article with others.

\subsection{Verification of the Hypotheses}

In this subchapter, the main data analysis to answer the research question "Do readers recognize Native Ads as advertising and how does this form of advertising affect trust in the contributions? In order to answer the research question, the hypotheses made in advance are tested and evaluated. The answers are analysed in detail in order to draw correct conclusions.

\subsubsection{Testing the First Hypothesis (H1)}

In this chapter, the first hypothesis (H1) "In the experimental group, in contrast to the control group, the respondents will increasingly recognize the native ad as an advertising medium" is tested. Only the answers of the first category "respondents who recognized the article as advertising" are considered for the test. The reason for this is that these respondents recognized 
IADIS International Journal on WWW/Internet

the native ad. In the following, a null hypothesis (H01) is formulated for the first hypothesis (H1):

H01: In the experimental group, in contrast to the control group, the respondents will recognize the native ad reduced as an advertising medium.

The evaluation of the collected data was carried out with the help of the binomial distribution test. Since the null hypothesis assumes that the experimental group will recognize the article reduced as native ad, a relative frequency of $49 \%$ is expected. In the following, it is examined whether the observed probability differs significantly from the assumed expectation. The evaluations indicate an exact significance of the p-value of 0.519 . Since the p-value $(0.519)$ is greater than the determined significance level of $\alpha=0.05$, the null hypothesis can be assumed. Consequently, the first hypothesis (H1) must be rejected.

\subsubsection{Testing the Second Hypothesis (H2)}

The test of the second hypothesis $(\mathrm{H} 2)$ "A large proportion $(60 \%)$ of the respondents are likely to lose trust in the content of the contribution" is also carried out with the binomial distribution test. For this purpose, the Question "The article read no longer appears trustworthy" was used, which was asked after native advertising had been disclosed. In the following, the null hypothesis (H02) to be analysed is formulated:

H02: A large proportion (60\%) of the respondents are unlikely to lose trust in the content of the article.

The null hypothesis assumes that $60 \%$ of the respondents are unlikely to lose trust in the content of the article, which means that a relative frequency of $60 \%$ is expected. In this case, the system also examines whether the observed probability differs significantly from the assumed expectation. The results show an exact significance value of 0.168 . Consequently, the $\mathrm{p}$-value is greater than $\alpha=0.05$. The null hypothesis (H02) must therefore be accepted and the second hypothesis $(\mathrm{H} 2)$ rejected.

\section{DISCUSSION}

In this chapter, the results of the empirical investigation are discussed, together with the theoretical foundations. The discussion covers the following two areas: Recognition of the Native Ads and effects on trust in the content of the Native Ads. The results of the "attitude towards the article", which were analysed separately in the previous chapter, are summarised in this chapter with the effect on trust in the content of the native ad. This is intended to uncover possible connections. The research question is then answered on the basis of the findings obtained.

\subsection{Native Ad Recognition}

The results of the present study show that only five $(2 \%)$ of the 251 respondents were able to recognize the advertisement as native ad. When comparing the results with other studies, low values were also found. In the first study by Wojdynski and Evans (2016), with a comparable sample of 242 respondents, only $7 \%$ were able to identify the article as advertising. This low percentage is of particular interest since a large number of recommendations to improve the recognition of native ads have been applied in this study. According to Wojdynski and Evans 
(2016.), labels such as "sponsored content" or "advertising" thus lead to greater recognition of advertising. The article of the experimental group of our study therefore contained the label "Sponsored" and an additional disclosure text "This article was prepared by Commercial Publishing Tamedia in collaboration with Gesundheitsförderung Schweiz". In addition to the disclosure language, further recommendations by Wojdynski (2016a) were implemented in the study. Therefore, a logo of the advertiser as well as supplementary information on this logo was available. Nevertheless, the results show no significant difference in recognition of native ads between the two groups. We can state, that the measures recommended by the literature have not led to an increase in the recognition of native ads. The answers of the respondents from the experimental group indicate that the additional disclosure features, in particular the logo, led to a misinterpretation of the advertising form. These characteristics were sometimes referred to as banner advertising. It could also be determined that the disclosure features or their contents were hidden. With the precise answers of some respondents from the control group for the recognition of native advertising it is assumed that certain respondents are already familiar with the topic and therefore pay more attention to such labels. Consequently, it can be concluded that the disclosure condition in the present study had no significant influence on the recognition of native advertising or native ad.

\subsection{Trust in the Content of the Contribution}

It was assumed that the disclosure of native ad would significantly reduce the trust of the respondents. In order to identify a difference, the trust of the respondents was measured before and after the disclosure of native advertising. Although the results show a decrease in trust after the advertising content was disclosed, this reduction is not significant. This suggests that most respondents trust the content of the article. When comparing the respondents who perceived the native ad, no significant change in trust was found. The study by Wojdynski and Evans (2016) shows different reactions. The respondents who recognized the advertisement had a more negative perception of the credibility and consequently less trust in the article. Consequently, the present results contradict the research results of other studies. Respondents indicated that the article was helpful and therefore had a relevant content for the respondents. IAB Switzerland (2017) also recommends that the address, in this case through the article, should offer the reader added value. The article should convince the reader with relevant, advisory or entertaining content (IAB Switzerland, 2017). Respondents trusted the content, although having a negative attitude towards the native ad. An explanation for this followed in the further survey, in which the respondents stated that it makes no difference whether the content is a native ad as long as it is relevant or interesting. The available evidence may provide a reason for trust in the native ad after disclosure of the form of advertising. In addition, the majority of respondents stated that they did not feel deceived by the disclosure of native advertising. Consequently, the respondents may have been of the opinion that they were not subconsciously advertised and that they had no negative attitude towards the advertiser. 


\section{CONCLUSION}

The present study examined whether readers recognize native ads as advertising and how this form of advertising affects trust in the contributions. In order to answer this research question, a quantitative study was carried out. This showed that the majority of the respondents were unable to recognize the article as native ad. The results also showed that the experimental conditions, based on the additional disclosure characteristics, did not lead to an increased identification of this form of advertising, as initially assumed. Regarding the impact of native advertising on the trust in the contributions, a decrease after the disclosure of the advertising content could be determined, but this value did not prove to be significant. As a result, the pre-set assumption that a large proportion of respondents would lose trust could not be confirmed. In addition, the respondents are more positive about the form of advertising if the content is interesting and relevant to the reader. Therefore, the question arises as to whether the criticism of native advertising is justified. This states that the success of native advertising is related to the inability of readers to recognize native advertising. Although the success was not measured in the present study, it was nevertheless found that the majority of the respondents were unable to recognize the native ad. Hence, there could be a connection. Concluding, it can be said that native advertising leaves a positive impression on readers when interesting and relevant content is conveyed to them. However, using an inadequate strategy can also create risks such as loss of trust.

\section{LIMITATIONS}

The results of this study are limited to the format native advertorial, which is published on online media platforms. Consequently, the results should be applied to this specific format and not to other formats or application areas of native advertising. Due to the arbitrary selection of the respondents, there is a self-selection bias in the sample. Therefore, a generalization of the results to the population is not recommended. Future samples should also show a greater variance in age. In addition, a uniform group allocation (experimental group and control group) of the respondents could not be guaranteed. It should be noted that the use of a different article for the experiment can lead to differentiated results. Possible reasons for this would be the influence of personal preferences and interests with regard to the content of the article and the involvement of the advertiser or his brand. Furthermore, it was not possible to investigate whether the respondents had already been confronted with native advertising in advance or whether they were familiar with the topic of native advertising. Possible previous knowledge could have an effect on the results with regard to the recognition of native ads as well as the trust in the contributions. It should be noted that the evaluation of the results for the recognition of native ads could be different if other categories were formed. In addition, the answers for the category allocation could often not be clearly interpreted or concluded as to whether the article was recognized as a native ad. Assumptions, some of which had to be made, could also influence the available results. In view of these limitations and findings, there is a possibility that the results of this empirical study may have been impaired. 


\section{RECOMMENDATIONS}

In view of the findings from chapter 4, publishers are recommended to present the label (e.g. Sponsored) above the article heading more clearly, for example with a coloured background. This can increase the perception of the label as a sponsored article. Furthermore, the placement of additional disclosure features should be carefully selected. With regard to the results obtained in this study, it is not recommended to place the disclosure features, including a logo, on the right side of the page, as this is often misinterpreted or ignored. For an adequate positioning recommendation, further research should be consulted which has explicitly examined this issue. In addition, publishers are recommended to always use native advertising in a transparent manner. This can prevent the contents of online media platforms from losing credibility and readers from being suspicious of the contributions. In the long run, this can damage the reputation. Publishers and advertisers considering a future application of native advertising should not only ensure the disclosure of the content but also that it creates added value and is relevant for the target group. This can lead to a higher acceptance of native advertising by the readers. These recommendations are also addressed to publishers and advertisers who already use native advertising but have not taken this aspect into account. Based on the findings, it is recommended to develop a compliant strategy for the use of native ads content, presentation and selection to ensure a positive image. Since native advertising can offer an increase in value for publisher and advertisers as well as for readers.

\section{REFERENCES}

Adikari, S., \& Dutta, K. (2015). Real Time Bidding in Online Digital Advertisement. In B. Donnellan, M. Helfert, J. Kenneally, D. VanderMeer, M. Rothenberger, \& R. Winter (Hrsg.), New Horizons in Design Science: Broadening the Research Agenda (Bd. 9073, S. 19 - 38).

Alaimo, C., \& Kallinikos, J. (2018). Objects, Metrics and Practices: An Inquiry into the Programmatic Advertising Ecoystem. In U. Schultze, M. Aanestad, M. Mähring, C. Østerlund, \& K. Riemer (Hrsg.), Living with Monsters? Social Implications of Algorithmic Phenomena, Hybrid Agency, and the Performativity of Technology (Bd. 543, S. $110-123$ ).

Callejo Pinardo, P., \& Cuevas Rumin, R. (2016). Auditing Methodology to Assess the Quality of Online Display Advertising Campaigns. Universidad Carlos III de Madrid, Madid.

Content Marketing Institute (o.J.). What Is Content Marketing. Retrieved from https://contentmarketinginstitute.com/what-is-content-marketing.

Eugster, J. (2015). Die ganze Welt des Online-Marketings. November 2016. Wifimaku.com.

Hristev, S., \& Abou Nabout, N. (2014). Echtzeithandel von Werbung in Real-Time-Advertising. In Deutscher Dialogmarketing Verband e.V. (Hrsg.), Dialogmarketing Perspektiven 2013/2014.

Gertz, O., \& McGlashan, D. (2016). Consumer-Centric Programmatic Advertising. In O. Busch (Hrsg.), Programmatic Advertising (S. 55 - 73).

Gonzalvez-Cabañas, J.C. \& Mochón, F. (2016). Operating an Advertising Programmatic Buying Platform: A Case Study. International Journal of Interactive Multimedia and Artificial Intelligence, 3(6), 6.

IAB Switzerland, (2015). Programmatic Advertising. Wohin geht die Reise in der Schweiz? (Werbewoche 06).

IAB Switzerland (2017). Native Advertising Definition und Empfehlungen. Retrieved from https://www.iab-switzerland.ch/wp-content/uploads/2017/06/IAB-Native-Advertising-Leitfaden2017.pdf. 
IADIS International Journal on WWW/Internet

Kamps, I., \& Schetter, D. (2018). Performance Marketing: der Wegweiser zu einem mess- und steuerbaren Marketing - Einführung in Instrumente, Methoden und Technik. Wiesbaden: Springer Gabler.

Kosorin, D. (2018). Data in digital advertising: understand the data landscape and design a winning strategy.

Kreutzer, R. T. (2018). Praxisorientiertes Online-Marketing: Konzepte - Instrumente - Checklisten. 3. Auflage. Wiesbaden: Springer Gabler. DOI:10.1007/978-3-658-17912-0.

Lammenett, D. (2015). Praxiswissen Online-Marketing: Affiliate- und E-Mail-Marketing, Suchmaschinenmarketing, Online-Werbung, Social Media, Online PR (5., überarbeitete und aktualisierte Auflage). Wiesbaden: Springer Gabler.

Marti, A. (2017). NATIVE ADVERTISING - «SOFT LAW» AUF DEM VORMARSCH. Retrieved from https://www.fsdz.ch/file-docs/native_advertising_-_soft_law_auf_dem_vormarsch.pdf.

Offierowski, N. (2017). Programmatic Advertising. Voraussetzungen und Herausforderungen für kleine Mittelständische Unternehmen. München: Grin Verlag.

Ottersbach, T. (2018). Native ADs ist eine der effektivsten Werbeformen im Online-Marketing \#132. Retrieved from https://digitales-unternehmertum.de/native-ads-eineder-effektivsten-werbeformen-imonline-marketing-132.

Papadopolous, P., Rodriguez, P.R., Kourtellis, N., \& Laoutaris, N. (2017). If you are not paying for it, you are the product: how much do advertisers pay to reach you? Proceedings of the 2017 Internet Measurement Conference on - IMC ' 17.

Ryan, D. \& Jones, C. (2009). Understanding digital marketing: marketing strategies for engaging the digital generation. London; Philadelphia: Kogan Page.

Schäfer, A., \& Weiss, O. (2016). Understanding Demand-Side-Platforms. In O. Busch (Hrsg.), Programmatic Advertising (S. 75 - 86).

Schirmbacher, M. (2017). Online-Marketing- und Social-Media-Recht. 2. Auflage. Frechen: mitp Verlags $\mathrm{GmbH} \& \mathrm{Co} . \mathrm{KG}$.

Stallone, V. \& Klaas, M. (2019). The Digital Advertising Ecosystem Visualization - Literature Review. Held on the 12th IADIS International Conference on Information Systems 2019, Utrecht, The Netherlands

Yuan, S., Wang, J., \& Zhao, X. (2013). Real-time Bidding for Online Advertising: Measurement and Analysis. Held on the International Workshop on Data Mining for Online Advertising, Chicago, Illinois, U.S.A.

Zhu, X, Tao, H., Wu, Z., Cao, J., Kalish, K., Kayne, J. (2017). Ad Ecosystems and Key Components. In X. Zhu, H. Tao Z. Wu, J. Cao, K. Kalish, \& J. Kayne, Fraud Prevention in Online Digital Advertising. Cham: Springer International Publishing. 